\title{
The Influence of Financial Service Characteristics on Use Intention through Customer Satisfaction with Mobile Fintech
}

\author{
Lin-Lin Zhang and Ha-Kyun Kim \\ Pukyoung National University, 45, Yongso-ro, Nam-gu, Busan, South Korea \\ 123126501@daum.net, kimhk@pknu.ac.kr
}

\begin{abstract}
As the world's ICT technology develops, the application of new technology will facilitate the change and development of the financial industry as it moves into universal, microfinance and wisdom financing by providing services to niche markets. After reviewing previous studies on financial service characteristics, customer satisfaction and use intentions, an empirical study was conducted. Financial services are characterized by convenience, profitability, security and flexibility. The study aims to analyze what factors influence the intent of users to manage personal assets based on Fintech-based Alipay. This study used SPSS 22.0 for basic statistics and structural equations analyzed with Smart PLS 2.0 (partial least squares). The findings are as follows. First, the characteristics of financial services (convenience, benefits, security, and flexibility) give major influence on the increasing of customer satisfaction. Second, the increasing of customer satisfaction gives significant influence on use intentions. This means that in order to settle in the market, it is essential to establish differentiated financial services in a rapidly changing business market. In order to draw clients in the mobile market, it is necessary to actively use the characteristics of financial services.
\end{abstract}

Keywords: Convenience, Benefits, Security, Flexibility, Customer Satisfaction.

\section{Introduction}

Following the development of the information communications technology (ICT) after the U.S. sub-prime mortgage crisis, traditional financial companies have been using ICT to submit an application fresh. This has been constantly strengthened, and pioneering economic services companies have emerged, bringing financial technology development to a new stage. The term "fintech" was introduced in a paper by Bettingers (Lee and Choi 2018). Fintech collectively refers to new 
financial services that combine "finance" and "technology." New financial technologies using smart technologies, especially mobile, are promoting the efficiency of existing financial systems and promoting the ICT convergence of financial services (Chang and Kim 2017).

The application of new technologies will enable the financial industry to serve niche markets and promote change and development in universal, microfinance and wisdom financing. Recently, China's financial services industry has been transformed into "intelligent finance" in the 3.0 era. The efficiency and quality of financial services continue to increase. According to the recent five-year China Internet Development Statistics Report, Internet wealth management users continue to grow from 78.49 million in 2014 to 1.5 billion in 2018 .

Alipay, which started in 2004, was used as a secure third-party payment tool in the early days of China's e-commerce, but now uses blockchain, AI and other technologies and has developed into a multifunctional life service platform. It provides a variety of services, including hotel reservations, movie ticket purchases, utility bill payments, online hospital reception and asset management products.

"Flexibility" has been introduced as an important factor to consider in the financial services characteristics of mobile asset management. This is a preliminary variable to grasp the customer's use intention and helps to identify customer satisfaction.

The points of report are to empirically inspect the characteristics of financial services of asset management through Alipay for Chinese people, and to examine how it affects customer satisfaction and how that in turn affects use intention.

\section{Theoretical Background}

\subsection{Characteristics of mobile financial services}

The financial industry is an area where IT technology is introduced faster than other industries (Jung 2017). Mobile finance is a combination of "wireless," "online" and "finance." It means wireless features available anywhere, the features of online services available at any time, and features of existing and new financial services (Lee 2001, Lee and Cho 2017). By integrating traditional finance and IT technology, the development trend of the financial industry has surpassed the limits of time and space, with advantages over traditional financial services such as flexibility and universality. The total global investment of the fintech industry stood at $\$ 1.1$ billion in 2008, and rose to $\$ 6.9$ billion in 2013 and $\$ 34.4$ billion in 2017 (Statista 2019).

Mobile financial services refer to electronic financial services using smart equipment like smart phones and tablet PCs (Yu 2017 and Kim 2018).

Convenience in use implies utility related to use, such as ease of movement, time and ease of operation (Gao 2019, Sekhar and Sarma 2018). Smart mobile refers to the degree to which users can use it conveniently (Kim and Lee 2012) 
because it is easy to carry and to operate for information. Increasing competition, along with socio-economic changes and technological advances, continue to drive customer demand for convenience. Companies are working hard to provide convenience as a means of effective customer management. Convenience, which was mainly researched on purchasing products, began to suggest convenience in the service field through research on retail stores. Convenience provided by service companies is delivered through information providing media. It is delivered not only to indirect and intangible services but also to customers through physical and human services. Convenience is recognized as a concept of minimizing the time and effort of an individual incurred in purchasing and using a service as a cost. The conveniences of each type by previous studies are as follows. First, decision convenience provides accurate information. This is a process that requires the customer's time and effort to purchase a service or make a purchase decision. Second, access convenience saves customers time and effort in meeting customers and using services. Third, convenience is the point in time when the service is provided. Discomfort is a key factor that can have a negative impact on the time and effort the customer perceives. Fourth, transaction convenience is related to reducing the cost of time and effort perceived after using the service. Fifth, ex post convenience is to compensate for unexpected service failures or defects after service use. The provision of additional services is related to the satisfaction of service recovery efforts.

Economic benefits refer to the extent of financial benefits consumers expect, such as interest rates and commissions, compared with existing financial firms. The service provider must secure the entity's interests with the establishment of a longterm relationship with the user, which provides relationship benefits, including economic, technological and social benefits (Chang and Kim 2017, Ahn 2016).

Information security can be seen as the level of belief in whether a user can use personal information securely when using the system or financial services (Jung 2017, Yoon and Kim 2018). Information security is defined by various researchers. It protects against threats so that the value or property of the information is not lost or disturbed. It can be seen as taking measures and measures to prevent misuse and abuse. Information security is not a physical harm, but can be regarded as a safety act in that it is necessary to prevent personal and organizational information and information-related physical damage and accidents. The importance of information management in organizations continues to grow. Increasingly, investments in information security technologies and policies are being made by organizations that want to focus on information management. Despite continued investment in information security, many organizations have a variety of information security threats that exist outside and inside the organization. It also faces information security incidents. In the financial industry, the information being protected consists of high-level customer information. There is a great interest in information security 
technology and policy. Security incidents in the financial industry are directly related to data loss. In the event of a security incident, the company is believed to directly damage financial companies and target customers. Looking at the types of information security incidents that occur in the financial industry, most accidents are caused by external intrusions. However, since security incidents by insiders account for more than $15 \%$ of all accidents every year, it is necessary to continuously control the threat of information disclosure by insiders.

The service has flexibility satisfy the various needs of customers. Flexibility was chosen as a variable because customers thought it was a significant aspect in choosing Alipay. Flexibility is a concept that is so vague that it is not easily understood. In general terms, flexibility refers to the adaptability of a particular organization or system to environmental changes. Historically, the term flexibility has been widely discussed in various fields of economic, decision-theoretic, and organizational perspectives. As an economical study, a plant with a relatively modest average cost curve is more flexible than other plants. Applying the economies of scope theory, a series of studies were conducted to explain that companies producing various items are highly competitive. Research from a decision-making point of view sees a large choice as a flexible alternative in uncertain decision making. Flexibility is defined as the ability of the decisionmaking process to respond to changing circumstances. Existing studies from the perspective of organizational theory examined the concept of organizational flexibility in organizational theory to cope with the rapidly changing environment. We analyzed the concept of flexibility from various angles, divided it into static and dynamic flexibility, and presented a framework for the concept of multidimensional flexibility that can be applied to the hierarchical structure of an organization.

\subsection{Customer satisfaction}

The comprehensive sense of purchaser has about the performance of an invention or service, either before or after buy, and can be defined by the client's expectations about the invention before and after purchase (Kwon 2008, Wu and Kim 2014). User satisfaction is the state of mind where users believe the effects of mobile use meet their expectations after using fintech services (Ha and Jung 2016, Ju and Yang 2017). The degree of satisfaction that consumers have before and after using a particular product or service changes depending on how consistent they are in assessing the expected consistency by comparing the initial expectations. They had and the perceived performance after use (Kim and Kang 2017, Park 2018). The concept of customer satisfaction has received a lot of attention from academia and industry since the 1970s. The concept of customer satisfaction is emerging as an important issue not only in academia but also in industry as it relates to various achievements that customers want from companies. By inferring the decision making process of customers, customer satisfaction is formed by perception of choice. Satisfied customers have higher loyalty and can be connected to reuse. 
Customer satisfaction is related to the quality of a company's products or services. It has aspects that contribute to customer retention and corporate profitability. The overall experience of the product or service purchased by the customer responds positively if it meets their expectations. Positive customer response leads to a psychological state of customer satisfaction. Explain that when emotions exceed expectations, they are extremely satisfied and happy. Companies that satisfy customers gain competitive advantage in various aspects such as high profits, entry barriers, and cost reduction. Customer satisfaction activity is a management technique that grasps products, services and corporate image from the standpoint of the company and the customer and reflects them in management activities. Much of customer satisfaction is determined by comparing the expectations you have of a product or service before you buy it with the results you feel after purchasing or consuming your product or service.

\subsection{Use intention}

It's a psychological decision that an innovation or service makes when it feels convenient, easy to use, and useful, the possibility of using the invention or service can be defined. Research on the acceptability of fintech services has shown that factors such as convenience, compatibility and practicality have a significant impact on acceptance (Jung 2017, Choi and Shin 2017, Kim 2019). The intention to use is to intend to visit or repurchase after the overall satisfaction with the product. It is the probability of a person's beliefs and attitudes appearing as a commitment to future behavior from the customer's point of view, and the possibility of reusing services through future service providers based on an evaluation of past experiences. Intention to use differs depending on the individual's personality, desires and social environment. Depending on the experience of the service or product, a plan in mind leads to action. In general, use intention is the concept of an individual's expected or planned future behavior. It is defined as the probability that an individual's attitudes and beliefs are translated into action or the subjective possibility that attitudes and beliefs are translated into action. Intention to use is an important antecedent for predicting and determining future behavior in research on the acceptance of various information technologies as well as research on general product purchase. Intention to use can be defined as the intention of users to adopt new technology. This has a direct impact on actual use and is the most immediate determinant of behavior.

\section{Research Design}

\subsection{Research model}

According to research on the characteristics of mobile fintech services, they are considered to give significant influence on the use intention. Therefore, the characteristics, convenience, benefits, security and flexibility of mobile fintech services were chosen as variables. In this study, we empirically study the factors 
that influence the intent of a customer to use mobile fintech services. For this purpose, a research model was designed as shown in [Figure.1].

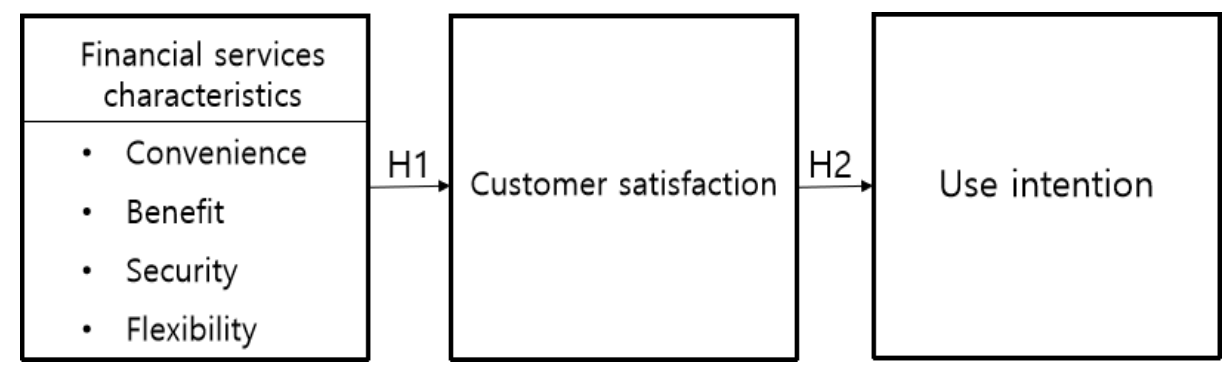

Fig. 1: Research Model

\subsection{Research hypotheses}

According to the research results, regarding the features of mobile banking services, the higher the user convenience, the higher the user satisfaction (Kim and Lee 2012). For mobile banking customers, they express great satisfaction because they can perform banking services at the time and place they want without time and space restrictions (Tak 2014, Kim and Reddy 2015). The less secure a mobile payment service is, the less positive the attitude towards it (Lee and Park 2016). Facts have proved that the economy and ease of use of mobile banking services give important influence on the increasing of customer satisfaction and loyalty (Kwon 2008). Unlike traditional financial institutions, it is free to register on Alipay, purchase asset management products, and withdraw funds from a single bank account or Alipay account according to customers' needs. It also allows for the flexible use of funds. Focused on preceding studies, hypotheses were established.

Hypothesis H1: Financial services characteristics will give significant influence on the increasing of customer satisfaction.

Hypothesis H1-1: Among financial service characteristics, convenience will give significant influence on the increasing of customer satisfaction.

Hypothesis H1-2: Among financial service characteristics, benefits will give significant influence on the increasing of customer satisfaction.

Hypothesis H1-3: Among the characteristics of financial services, security will give significant influence on the increasing of customer satisfaction.

Hypothesis H1-4: Among the characteristics of financial services, flexibility will give significant influence on the increasing of customer satisfaction.

Hypothesis on Customer Satisfaction and Use Intention: In previous studies on use intention in mobile banking, user satisfaction showed a positive effect on acceptance intention (Kim and Lee 2012). In many other previous studies, the higher the customer satisfaction, the higher the customer's use intention. Therefore, the following hypothesis is set. 
Hypothesis H2: The increasing of customer satisfaction will give positive influence on the improving of use intention.

\subsection{Empirical Analysis and Results}

A total of 55 Chinese Alipay users participated in the survey, which was conducted for 20 days starting on August 5, 2019. The basic statistics of the survey are as follows: $32.73 \%$ of the respondents were male and $67.27 \%$ were female. As for age groups, $1.82 \%$ were in their $10 \sim 19 \mathrm{~s}, 38.18 \%$ were in their $20 \sim 29 \mathrm{~s}, 50.91 \%$ were in their 30 39s, 3.64\% were in their 40 49s and 5.45\% were over 50 years old. Regarding education, $10.91 \%$ were below high school, $1.82 \%$ were college students, $74.55 \%$ were university graduates, and $12.73 \%$ were in graduate school or above. In terms of employment, $20 \%$ were self-employed, $21.82 \%$ were white collar, $14.55 \%$ were professional, $5.45 \%$ were students, and $38.18 \%$ had other jobs.

Data Analysis: In order to analyze data, SPSS 22.0 and Smart PLS 2.0 were used for basic statistics and structural equation analysis, respectively. Convergent validity is tested based on the factor loading value, composite reliability (CR), and average variance extracted (AVE) from each factor. Since the factor loading value, $\mathrm{CR}$, and AVE were higher than 0.6,0.7, and 0.5, respectively, convergent validity was verified. Discriminant validity is tested by comparing the square root of AVE and the correlation coefficients. Since the square root of AVE was greater than the correlation coefficients, discriminant validity was also verified. 
Table 1: Reliability and Internal Consistency

\begin{tabular}{|c|c|c|c|c|}
\hline Variables & Factor Loading & AVE & C. $\mathbf{R}$. & Cronbach's $\alpha$ \\
\hline \multirow{2}{*}{ Convenience } & 0.881 & \multirow{2}{*}{0.822} & \multirow{2}{*}{0.902} & \multirow{2}{*}{0.788} \\
\hline & 0.932 & & & \\
\hline \multirow{2}{*}{ Benefit } & 0.880 & \multirow{2}{*}{0.770} & \multirow{2}{*}{0.870} & \multirow{2}{*}{0.702} \\
\hline & 0.875 & & & \\
\hline \multirow{2}{*}{ Security } & 0.917 & \multirow{2}{*}{0.857} & \multirow{2}{*}{0.923} & \multirow{2}{*}{0.833} \\
\hline & 0.934 & & & \\
\hline \multirow{2}{*}{ Flexibility } & 0.931 & \multirow{2}{*}{0.861} & \multirow{2}{*}{0.925} & \multirow{2}{*}{0.383} \\
\hline & 0.924 & & & \\
\hline \multirow{2}{*}{$\begin{array}{c}\text { Customer } \\
\text { satisfaction }\end{array}$} & 0.881 & \multirow{2}{*}{0.773} & \multirow{2}{*}{0.872} & \multirow{2}{*}{0.707} \\
\hline & 0.878 & & & \\
\hline \multirow{2}{*}{ Use intention } & 0.917 & \multirow{2}{*}{0.822} & \multirow{2}{*}{0.903} & \multirow{2}{*}{0.784} \\
\hline & 0.897 & & & \\
\hline
\end{tabular}

Table 2: Correlation and Discriminant Validity

\begin{tabular}{|c|c|c|c|c|c|c|c|c|}
\hline Variables & AVE & 1 & 2 & 3 & 4 & 5 & 6 & 7 \\
\hline Convenience & 0.822 & 0.907 & & & & & & \\
\hline Benefit & 0.770 & 0.523 & 0.878 & & & & & \\
\hline Security & 0.857 & 0.509 & 0.594 & 0.926 & & & & \\
\hline Flexibility & 0.861 & 0.458 & 0.659 & 0.629 & 0.928 & & & \\
\hline $\begin{array}{c}\text { Customer } \\
\text { satisfaction }\end{array}$ & 0.773 & 0.641 & 0.735 & 0.715 & 0.735 & 0.879 & & \\
\hline Use intention & 0.822 & 0.465 & 0.654 & 0.726 & 0.729 & 0.745 & 0.907 & \\
\hline
\end{tabular}

\subsection{Verification of Research Model}

For the structural model, Smart PLS 2.0 was used. The path coefficient and the coefficient of determination (R2) between the variables of the research model were derived with the structural model. The coefficient of determination (R2) for 
customer satisfaction (0.744) and use intention (0.555) was "high."

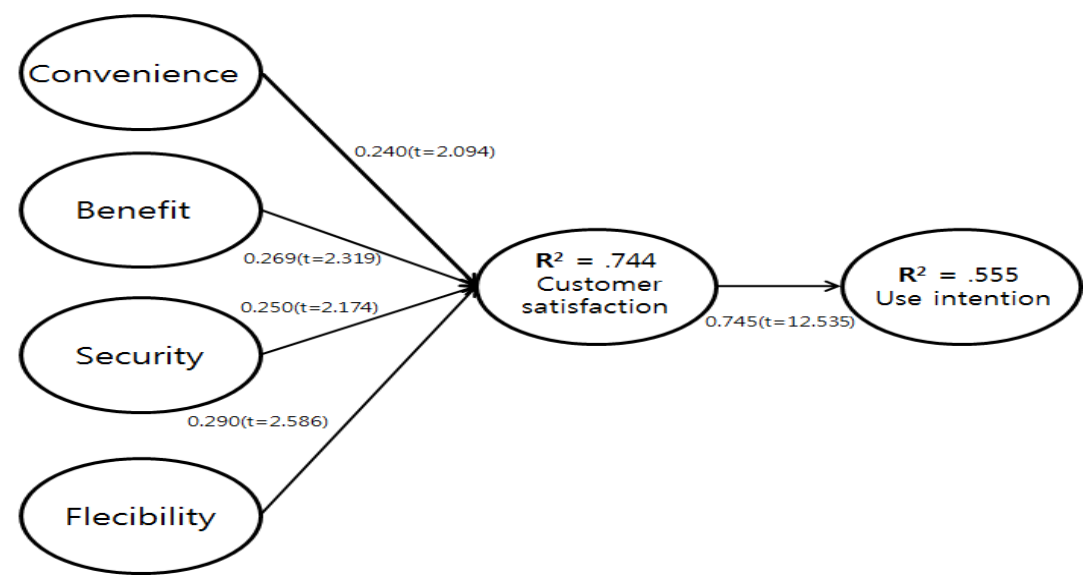

Fig. 2: Verification of Research Model

Hypothesis H1-1, "Among financial service characteristics, convenience will give positive influence on the increasing of customer satisfaction," was statistically significant at a significance level of $97.5 \%$ of $(\mathrm{H} 1-1 ; \beta=0.240, \mathrm{t}=2.094, \mathrm{p}<0.05)$. Therefore, Hypothesis H1-1 was adopted. Hypothesis H1-2, "Among financial service characteristics, benefit will give positive influence on the increasing of customer satisfaction," was statistically significant at a significance level of $97.5 \%$ of $(\mathrm{H} 1-2 ; \beta=0.269, \mathrm{t}=2.19, \mathrm{p}<0.05)$. Hypothesis $\mathrm{H} 1-2$ was also adopted. Hypothesis H1-3, "Among the characteristics of financial services, security will give positive influence on the increasing of customer satisfaction" was statistically significant at a significance level of $97.5 \%(\mathrm{H} 1-3 ; \beta=0.250, \mathrm{t}=2.174, \mathrm{p}<0.05)$. Hypothesis H1-3 was adopted. This means that among the factors of financial services characteristics affecting customer satisfaction, security is significant. Hypothesis H1-4, flexibility will give significant influence on the increasing of customer satisfaction $(\beta=0.290, \mathrm{t}=2.586, \mathrm{p}<0.05)$ was also adopted. Hypothesis $\mathrm{H} 2$, "the increasing of customer satisfaction will give positive influence on the improving of use intention," was significant $(\mathrm{H} 2 ; \beta=0.745, \mathrm{t}=12.535, \mathrm{p}<0.05)$, and therefore was adopted. Customer satisfaction is significant in use intention. 
Table 3: Hypothesis Test Results

\begin{tabular}{|c|c|c|c|}
\hline Hypothesis Path & $\begin{array}{c}\text { Standardized } \\
\text { Coefficient }(\boldsymbol{\beta})\end{array}$ & t-value & Decision \\
\hline H1-1: Convenience $\rightarrow$ Customer satisfaction & 0.240 & 2.094 & Accept \\
\hline H1-2: Benefit $\rightarrow$ Customer satisfaction & 0.269 & 2.319 & Accept \\
\hline H1-3: Security $\rightarrow$ Customer satisfaction & 0.250 & 2.174 & Accept \\
\hline H1-4: Flexibility $\rightarrow$ Customer satisfaction & 0.290 & 2.586 & Accept \\
\hline H2: Customer satisfaction $\rightarrow$ Use intention & 0.745 & 12.535 & Accept \\
\hline \multicolumn{2}{|r|}{$\mathrm{t}=1.97^{*}, \mathrm{p}<0.05$} & \\
\hline
\end{tabular}

\section{Conclusion}

China's Fintech industry has grown rapidly along with the development of the world's ICT. Alipay has grown from a secure third-party payment tool to a lifestyle service platform. With Alipay, people not only make payments, but also hotel reservations, buy movie tickets, pay bills, receive online hospitals, and manage their assets. In particular, Yu'ebao, an asset management product, attracted the attention of many people at the same time. Therefore, this study carried out an empirical analysis on how the characteristics of Fintech services affect the intentions of people who use Alipay asset management products.

The results of the study are as follows. Hypothesis 1 on the characteristics of financial services and customer satisfaction was adopted. In other words, among financial service characteristics, convenience, benefits, security, and flexibility influenced customer satisfaction. Hypothesis 2 about customer satisfaction and use intention was adopted. In other words, customer satisfaction gives positive effect on use intention.

Focused on the results of this paper, the implications of report can be suggested.

First, flexibility was found to have the greatest impact on customer satisfaction. To be competitive, financial companies need to increase the flexibility of their products and services, including subscriptions for various customers, withdrawals, and use of funds.

Second, convenience, benefits and security also have a big impact on customer satisfaction. To be competitive, asset management products need to be developed more easily than traditional asset management methods, require customers to 
benefit more, and privacy must be designed more securely.

Third, the most important thing is to secure customer satisfaction. It was found that customer satisfaction gives great influence on use intention. Therefore, it is most important for financial companies to develop financial products with customer satisfaction in mind.

\section{References}

Ahn, B. 2016. Economic Analysis of the EDISON (EDucation-to-industry Integration through Simulation on the Open platform and Net) - focused on direct benefits. Asia-Pacific Journal of Educational Management Research, 1(1):155-160.

Chang, J. and Kim, K. 2017. What makes people keep using Fintech payment service? In the perspective of herding behavior theory and trust. The E-Business Studies, 18(2): 197-212.

Choi, D. J. and Shin, Y. T. 2017. A Study on the Intention to Use Reward App. Asia-pacific Journal of Convergent Research Interchange, 3(4): 73-83.

Gao, H. 2019. A Study on Intention to Use Fintech Service: Focusing on Fintech users in Korea and China. Doctoral dissertation, Keamyung University.

Ha, S. and Jung, H. 2016. The Impact of Fintech User and Product Characteristics on Intention for Continuous Use. Information Policy, 23(4): 59-75.

Ju, Y. H. and Yang, H. C. 2017. The Effects of HMR Choice Attributes on Shopping Satisfaction and Intention to Pay Premium Price: Focusing on the Role of Involvement. International Journal of IT-based Management for Smart Business, 4(2):13-18.

Jung, T. 2017. A Study on the Effect of Fintech Financial Services Characteristics on Acceptance Intention: Focusing on mobile banking. Doctoral dissertation, Pusan National University.

Lee, S and Park, W. 2016. A Study on the Intention of the Use of Mobile Payment Services: Application of the Technology Acceptance Model. Korean Management Science Review, 33(2): 65-74.

Lee, T. and Choi, Y. 2018. The Study on Quality Factors for Customers Satisfaction in Fintech Service. Journal of Korea Service Management Society, 19(3): 159-188. 
Lee, K. 2001. Comparison of Domestic and International Mobile Financial Services. KISDI IT FOCUS: 42-44.

Park, G. 2018. A Study on the Effect of Consumption Value Orientation and Mobile Familiarity on Buying Intention. International Journal of IT-based Management for Smart Business, 5(1):17-22.

Kwon, H. 2008. A Study on the Effect of Service Quality of Internet Banking and Mobile Banking on Customer Satisfaction. Master's Thesis, Sookmeong Women's University, Korea.

Kim, M. 2018. The Impacts of Financial Reforms on Households' Savings Behavior. International Journal of IT-based Social Welfare Promotion and Management, 5(1):7-12.

Kim, S. and LEE, L. 2012. Factors Affecting the Intention to Use of Smart-Phone Banking Service: A Case of Chinese Users. The Journal of the Korea Contents Association, 12(11):303-312.

Kim, H. K. 2019. An Empirical Study Affecting Content Characteristics of Cyber Culture on Acceptance Intention. Asia-pacific Journal of Convergent Research Interchange, 5(3): 63-70.

Kim, H. and Kang, S. 2017. The Effects of Product and Customer Characteristics on Product Adoption in Mobile Banking Service: Focused on Mediating Roles of Customer Experience. Journal of Marketing Management Research, 22(4): 3-29.

Kim, J. H. and Reddy, R. S. 2015. Implementation of Mobile Apps Across Globe and Challenge to Software Engineering. Asia-pacific Journal of Convergent Research Interchange, 1(3):1-16.

Ryu, G. M. Shin, J. H. Lee, S. and Cho, K. W. 2017. Development of Online Engineering Education System using Web-based Computational Science Platform, International Journal of Computer Science and Information Technology for Education, 2(2):13-18.

Sekhar, C. and Sarma, A. V. 2018. Automatization of Accounting and Payment Release Process of ESDM Scheme. World Journal of Accounting, Finance and Engineering, 2(1):43-52.

Statista, 2019. Value of Fintech Investments Globally 2008-2018. 
Tak, I. 2014. A Study on User Satisfaction Factors of Mobile Banking Service Using Smartphones. Namseoul University of Korea.

Yu, S. 2017. A Study on Developed Security Check Items for Assessing Mobile Financial Service Security. Master's Thesis, Chung-Ang University, Korea.

Yoon, J. Shin, Y. Kim, J. 2018. A Study on the Information Security Management Index through Analysis of EU-GDPR(European Union-General Data Protection Regulation). Asia-pacific Journal of Law, Politics and Administration, 2(2):13-32.

Wu, B. and Kim, H. 2014. Consumer Perception and Satisfaction towards Online Shopping. International Journal of Smart Business and Technology, 2(2):35-42.

Zhang, L. and Kim, H. 2019 An Empirical Study on Effecting Characteristics of Financial Services on Use Intention: Focusing on Asset Management of Mobile FinTech Using Alipay. International Journal of Business Policy and Strategy Management, 6(1): 31-36. 